\title{
Influence of occlusal anatomy on acrylic resin CAD/CAM crowns fracture load and stress distribution
}

\begin{abstract}
Alexandre Luiz Souto Borges ${ }^{1}$, Aline Lins de Lima ${ }^{1}$, Larissa Mendes Campaner ${ }^{1}$, Marco Antonio Bottino ${ }^{1}$, Amanda Maria de Oliveira Dal Piva ${ }^{1}$, João Paulo Mendes Tribst ${ }^{1}$

${ }^{1}$ Department of Dental Material and Prosthodontics, São Paulo State University, Institute of Science and Technology - São José dos Campos, SP, Brazil.
\end{abstract}

\section{Abstract}

Objectives: This study compared the influence of occlusal anatomy on acrylic CAD/CAM crowns fracture load and stress distribution. The null hypothesis was that there would be no difference between the provisional crowns fracture load and stress according to different occlusal anatomy.

Methods: A full-crown preparation was simulated using dentin analogue (G10, Protec, São Paulo, Brazil) totaling 20 identical preparations. Next, twenty acrylic crowns were milled using different occlusal design parameter (Young or Adult) available in the software database. The crowns were cemented (Temp-bond, NE Kerr Dental, Brea, CA, USA) and fractured using a compressive load $(0.5 \mathrm{~mm} / \mathrm{min}$ of cross-head speed). Data were analyzed by using one-way ANOVA and Tukey tests $(p<0.05)$. A similar geometry was modeled and exported to the analysis software to perform a static structural analysis. The maximum principal stress was calculated using the finite element method with $300 \mathrm{~N}$ chewing load simulation.

Results: The occlusal anatomy significantly influenced the load-to-fracture $(p<0.05)$. Young design showed lower fracture load $(1139 \pm 132 \mathrm{~N})$ than Adult design $(2007 \pm 345 \mathrm{~N})$. The tensile stress distribution showed a similar pattern for both groups however the highest stress peak was calculated for Young design (76 MPa) in the occlusal surface.
Conclusion: The anatomy design with higher cusp angulation and occlusal sulcus more evident can increase the stress concentration and reduce the fracture load for acrylic resin CAD/CAM crowns.

Key words: Finite Element Analysis; Computer-Aided Design; Crowns; Acrylic Resins; Weight-Bearing.

Citation: Borges ALS, et al. (2021) Influence of occlusal anatomy on acrylic resin CAD/CAM crowns fracture load and stress distribution. Dentistry 3000. 1:a001 doi:10.5195/d3000.2021.118 Received: October 10, 2020 Accepted: February 2, 2021 Published: May 6, 2021

Copyright: (C2021 Borges ALS, et al. This is an open access article licensed under a Creative Commons Attribution Work 4.0 United States License. Email: joao.tribst@gmail.com

\section{Introduction}

Temporary crowns are indicated to be used as an intermediate restoration between the time of tooth preparation and the final indirect restoration procedure $[1,2]$. There are two major approaches for fabrication of temporary crowns: direct (manual) and indirect methods (CAD/CAM) [1].
Computer-aided design and computer-aided manufacturing (CAD-CAM) method allow the manufacture of acrylic crowns in pre-polymerized conditions, which improves mechanical properties, reduces discoloration, and increases the anatomy precision and reduces the marginal gap [3]. Another advantage of polymerbased CAD/CAM materials is their good machinability [4].
The literature reports that the provisional CAD/CAM fixed dental prosthesis [5] and crown [1] exhibit a higher mechanical strength compared to directly fabricated, when manufactured with the same material [5].

Despite the restorative technique, another factor that was strongly linked to fractures of dental restorations is their occlusal anatomy. For ceramic crowns, the 
cusp angles can influence the prosthesis's resistance and the stress concentration $[6,7]$. However the occlusal geometry and and fissure radius are still inconclusive [7]. Basically, crowns with thicker margins, smaller convergence angle and fully bonded are recommended for increasing fracture resistance final restorations [8]. This can be justified because a greater crown thickness and cusp angle resulted in a higher crack initiation load [9]. However, these information were not available for acrylic resin CAD/CAM crowns. Based on this, the aim of the current study was to investigate the influence of different occlusal anatomy patterns on the fracture behavior of acrylic resin full-crown restorations. The null hypothesis was that there would be no difference between the provisional crowns fracture load and stress according to different occlusal anatomy.

\section{Methods}

Twenty (20) crown preparations were machined in epoxy resin (G10, Protec, São Paulo, Brazil) using CAD/CAM (Computer Aided Design/Computer Aided Machine) technology. The use of this dentin analogue has been previous validated in literature $[10,11]$, and its usage allows the samples standardization with a homogeneous substrate, reducing the bias associated with the complexity of mechanical properties in natural human teeth. The occlusal and axial walls were uniformly reduced $(1.5 \mathrm{~mm})$. The preparations presented rounded internal angles, chamfer preparation, and total occlusal convergence of $20^{\circ}$. The abutments were cleaned in an ultrasonic bath with distilled water for $5 \mathrm{~min}$ and embedded in selfcured polyurethane resin $(25 \mathrm{~mm}$ $\varnothing \times 20 \mathrm{~mm}$ height) up to $1.5 \mathrm{~mm}$ bellow the chamfer [10]. Polyether (Impregum F, 3M ESPE) was used to simulate the periodontal ligament [12]. According to the literature, the root embedment using polyether material as periodontal ligament simulator have a significant effect on fracture resistance and can modify the root fracture modes [13]. While the present study was not expecting to observe root fractures before the provisional crown fracture, the periodontal ligament simulation was performed to allow a proper load dissipation.

A thin layer of titanium dioxidebased powder was sprayed onto each abutment for scanning (inEos Blue, inLab SW4.2, Sirona, Benshein, Germany) and subsequent crown design. For that, the Cerec inLab (Sirona for Dental Systems, Benshelm, Germany) database was used to provide the restoration anatomy information, and two shapes of crowns were obtained: "Adult"

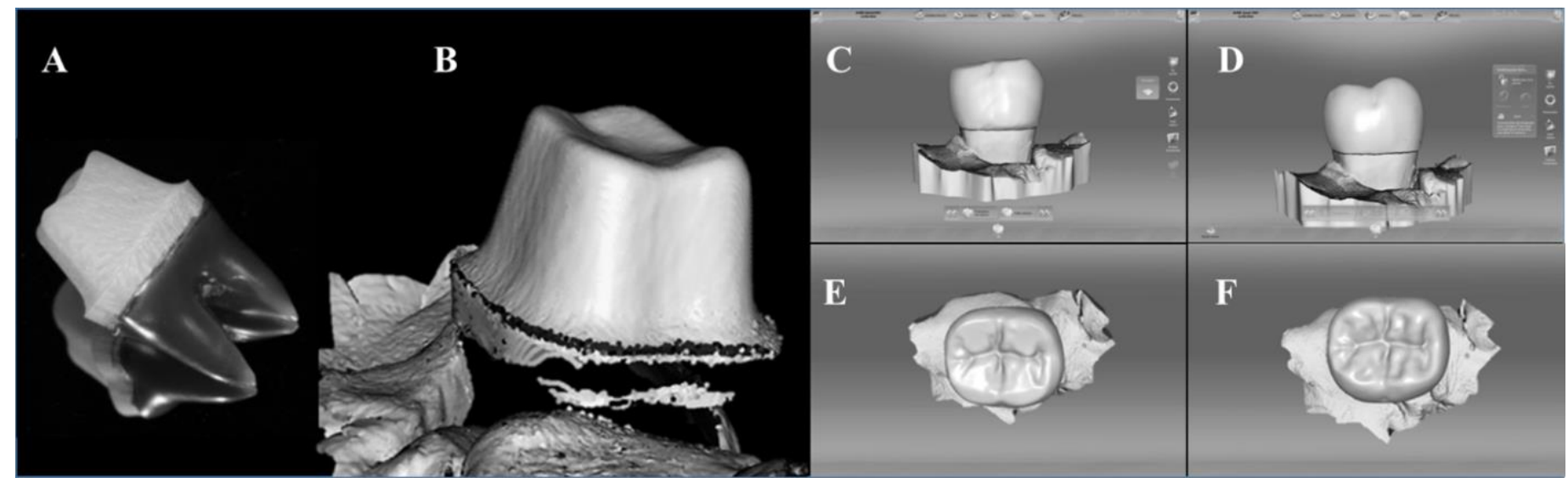

Figure 1. Sample preparation. A) Prepared abutment tooth, B) Digital impression in CAD software, C) Buccal view from Adult design crown, D) Buccal view from Young design crown, E) Occlusal view from Adult design crown and F) Occlusal view from Young design. 
(AD - plane cusp) and "Young" (Yhigh cusp heights) (Figure. 1).

The CAD/CAM temporary acrylic crowns (Vita Zahnfabrick, Bad Säckingen, Germany) were randomly allocated in groups according to the anatomy shape $(n=10)$.

The G10 preparations were etched with $10 \%$ hydrofluoric acid (HF) for $60 \mathrm{~s}$, washed with air/water jet for $30 \mathrm{~s}$, and then dried [14]. The intaglio surface of each crown was air-abraded with $50 \mu \mathrm{m}$ alumina particles at a pressure of 20 bar from a $10 \mathrm{~mm}$ distance for $50 \mathrm{~s}$ in each face with a constant particle incidence angle at 45․

The cement (Temp-bond, NE Kerr Dental, Brea, CA, USA) was manipulated in 1:1 ratio and applied onto the intaglio surface of the crowns, which were then placed on the respective abutment and kept in a $750 \mathrm{~g}$ weight for $5 \mathrm{~min}$. After the working time, the excess cement was carefully removed (Figure 2 ). The cemented restorations were stored in $37^{\circ} \mathrm{C}$ distilled water for $24 \mathrm{~h}$ before the fracture test.

Each crown was submitted to single load to fracture test (load cell of $1000 \mathrm{kgf}$ and $0.5 \mathrm{~mm} / \mathrm{min}$ of cross-head speed) in a universal testing machine (DL-1000, EMIC, São José dos Pinhais, Brazil). The data was recorded as the mean load value (in N) of both groups. The maximum load to fracture data were statistically analyzed using one-way analysis of variance (ANOVA) and the post-hoc Tukey multiple range tests $(\alpha=0.05)$ [15].

\section{Finite Element Analysis}

A three-dimensional (3D) model of an upper first molar was used to evaluate the tensile stress of the resin crown. The model containing root, pulp chamber, periodontal ligament, medullary and cortical bones was imported to Rhinoceros
CAD software (version 5.0 SR8, McNeel North America, Seattle, USA). For each group (Young and Adult), the anatomy previous provided by the database during the sample preparations was exported as STL file to the CAD software and converted to NURBS using a reverse engineering plugin.

The volumetric solids were imported to the analysis software (ANSYS 16.0, ANSYS Inc., Houston, USA) in STEP (STandard for the Exchange of Product model data) format. A mesh convergence test (10\%) determined 331538 nodes and 223955 tetrahedral elements for the Young design; and 3252248 nodes and 197852 elements for the Adult design preparation (Figure 3).

The contacts were considered perfectly bonded. The static structural mechanical analysis was performed loading the groups with $300 \mathrm{~N}$ distributed at contact areas and the base constrained
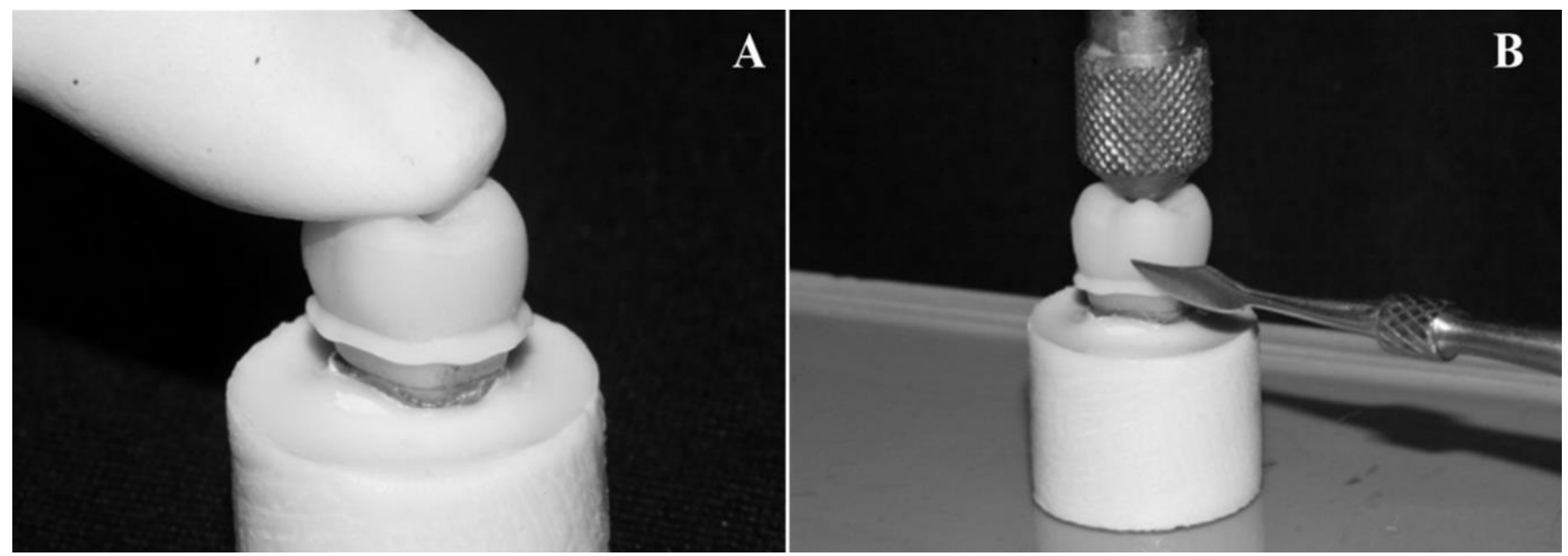

Figure 2. Luting procedure in A) Crown sitting with digital pressure and B) Excess cement removal. 

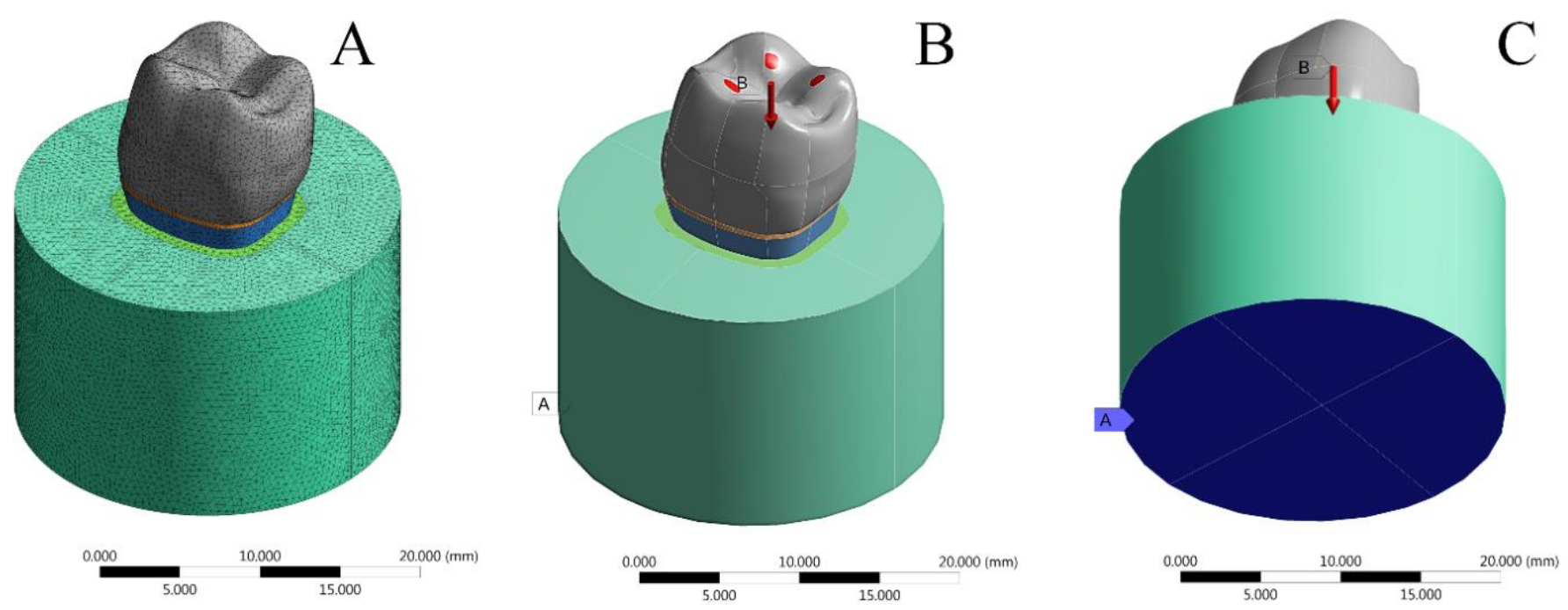

Figure 3. Boundary conditions simulated in finite element analysis. A) Mesh division, B) occlusal load contact points and C) fixed support.

following the experimental setup

[16]. The Maximum Principal

Stress criterion was used for analysis of the tensile stress concentration. Results were plotted in stress maps and the peaks recorded for quantitative comparison. Table 1 shows the material properties used for the finite element analysis.

Table 1. Material properties used for the finite element analysis.

\begin{tabular}{ccc}
\hline $\begin{array}{c}\text { Materials } \\
\text { Polyurethane }\end{array}$ & $\begin{array}{c}\text { Elastic Modulus } \\
(\mathbf{G P a})^{*}\end{array}$ & $\begin{array}{c}\text { Poisson } \\
\text { ratio* }\end{array}$ \\
Polyether & 3.60 & 0.30 \\
Dentin analogue & 0.05 & 0.45 \\
Cement & 17.90 & 0.32 \\
Acrylic resin & 5.50 & 0.30 \\
\end{tabular}

\footnotetext{
*Characterization done by an acoustic excitation pulse.
}

The Young design concentrated more stress compared to Adult design restorations (Figure 4). The higher the cusp angle, the higher the stress concentration in the crown's intaglio surface and occlusal surface. The tensile stress peak values are $76 \mathrm{MPa}$ for Young design and $35 \mathrm{MPa}$ for Adult design. The stress concentration regions for both groups suggest that the failure origin will be located in the occlusal sulcus.

\section{Discussion}

The goal of this study was to evaluate the effect of CAD/CAM acrylic crowns occlusal anatomy on the fracture behavior; it was observed that the design influenced the crowns' fracture load and stress concentration, leading to rejection of the study's hypothesis. 

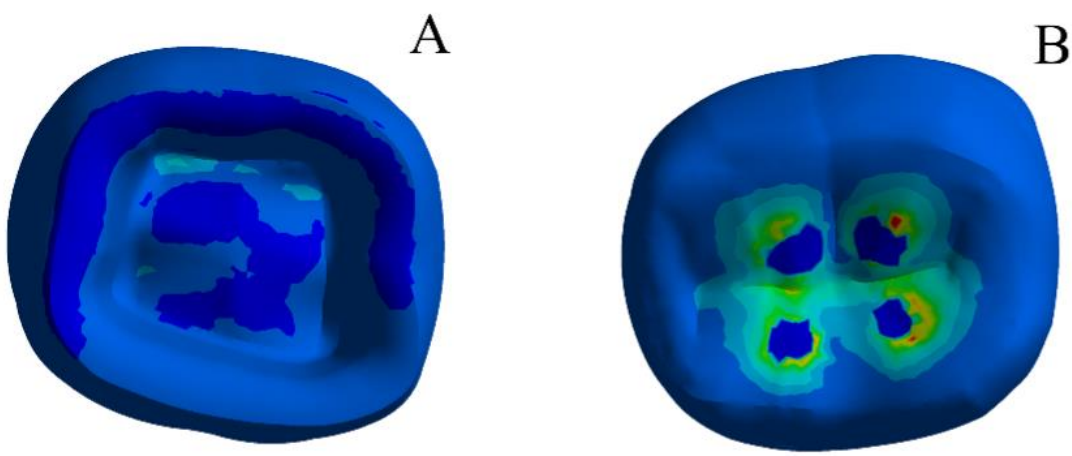

$\mathrm{D}$
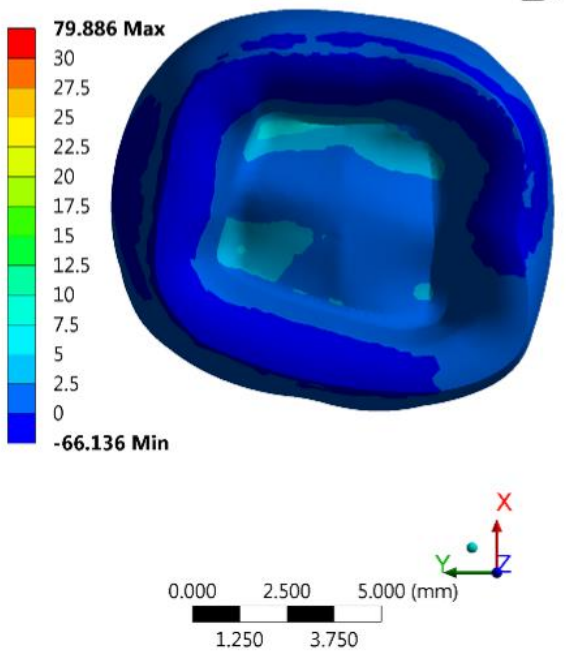

B

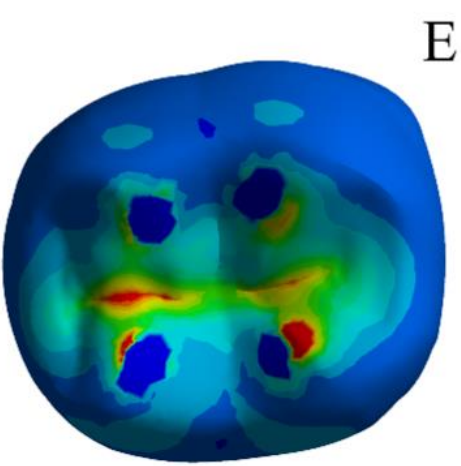

$\mathrm{E}$

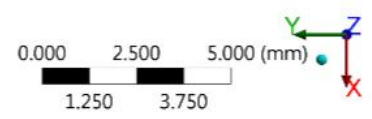

$\mathrm{C}$

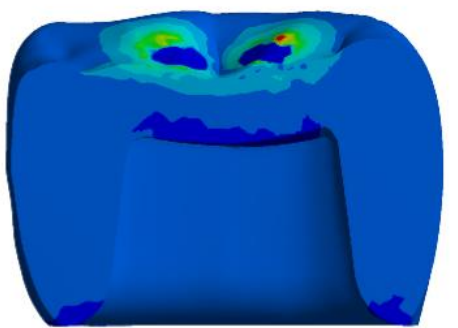

$\mathrm{F}$
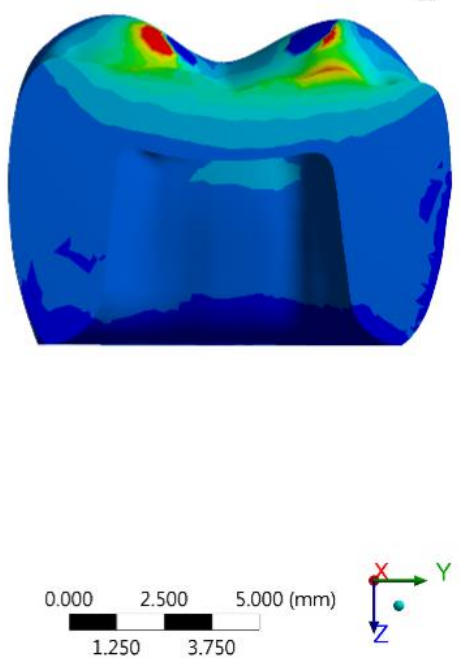

Figure 4. Maximum principal stress maps results for the restoration with A-C) Adult design and D-F) Young design.

Provisional crowns are expected to have sufficient resistance against bite forces. A previous study [17] investigated the maximum human bite forces; for female they found a bite force ranging from $108.9 \mathrm{~N}$ to $834.6 \mathrm{~N}$ (mean of 424.2) and from $262.8 \mathrm{~N}$ to $999.3 \mathrm{~N}$ (mean of 587.2 ) for male. In our study, the fracture load of the acrylic crown had a value above the average bite strength values for both genders.

A previous study [18] reported that there is no significant difference for the fracture resistance between provisional crowns using the chamfer preparation with a width ranging from $0.6 \mathrm{~mm}$ to $1 \mathrm{~mm}$. The present study complements this information suggesting that the failure will start in the occlusal surface and the anatomy should be more relevant for the maximum fracture load on acrylic resin CAD/CAM crowns.

The most important role that a provisional restoration plays is to stabilize and protect the existing tooth structure after tooth preparation. Besides, temporary crowns also act as interim prosthesis in cases where treatment gets delayed as in orthodontics or implants. Therefore, temporary materials are required to be tough and fracture resistant [19]. Based on this, the present study suggests that the use of Young design should be careful indicated since it presents higher stress concentration and lower load to fracture values, suggesting a higher failure possibility.

Despite the fitting accuracy of CAD-CAM restorations, an ideal occlusal surface is difficult to design, since it demands determining the dynamic relation 
between the dental arches, even if the CAD database already present a generic restoration anatomy [20]. In this sense, the use of Young or Adult morphology can be used as a predominant factor to create the occlusal shape, however the contact points should be based in the antagonist tooth and individualized for each case.

A previous report [21], found that full-crowns made using dental database with the antagonist design technique had a significantly smaller occlusal vertical discrepancy than those made with only correlation design technique; and that the use of the dental database with antagonist design provides the most accurate technique. The present study complements this report suggesting that the acrylic crown anatomy should be based in the patient's occlusion also and not only in database anatomy.

The major difference between both crown's design simulated in the present study was the cusp angle and occlusal sulcus. Despite both designs share the same clinical indication and can be manufactured for the same clinical case, the Young design presents a more detailed anatomy. The explanation for the worst biomechanical behavior for the Young design is because the cusps of posterior teeth substantial increased the bending and flexural loads during functional and parafunctional occlusal movements. These applied loads can theoretically generate a horizontal force component which tends to open up the principal sulcus space increasing the tensile stress concentration and subsequent creating cracks at the bottom of the fissure $[22,23]$. The present study corroborates with this statement since the numerical simulation showed an increased stress magnitude when the Young anatomy was used.

A previous finite element study suggest that the cusp angle can modify the loads incidence for provisional endocrowns restored molars [23]. The same indication can be performed for the present study considering only the fracture load and stress concentration for acrylic resin crowns. A 3D computer model can be used to simulate various conditions with numerous simulation parameters [24], however destructive mechanical tests, such as fracture load tests, are important for biomechanical analysis of tooth and dental restorative materials, as they enhance understanding of the behavior of teeth in high loading situations [25]. Usually, areas of high stress concentration eventual failures are more expected to occur [26] and both methodologies can be associated to perform a properly investigation from the fracture mechanics [27].

In conventional acrylic resin restorations, the cross-linking agent may lead to variation in the material performance [28]. The results of the present study support the use of CAD/CAM, which may reduce voids in the composite, allowing for controlled polymerization and a more homogeneous matrix.

According to an in vitro study [9] any surface irregularity including the sharp occlusal notch can be considered as a discontinuity in the microstructure of the material which can predispose the crown to crack initiation. Factor that can be reduced using an Adult design tooth anatomy.

However, reducing the cusp angle and simplifying the tooth anatomy, can negatively affect the patient's masticatory efficiency and muscular activity when used for artificial tooth in removable partial dentures $[24,29]$. The present study suggests, however that the use of simplified anatomical tooth can be positive for temporary crowns, in a shortterm period of use until the final restoration can be cemented. 
As strengths of the present methodologies, the fracture load is an important method employed to evaluate the ultimate strength of restored posterior teeth during compressive load fracture test [30]. This mechanical test is usually performed associating the influence of different factors that can affect simultaneously the restoration success [30,31]. In addition, the finite element method is extensively applied in dental materials mechanical assessment, allowing the simulation of different structures that compose the dental restoration [2,6,10,16,22-27]. This numerical approach allows the stress maps visualization and quantitative measurements of stress peaks, indicating with acceptable precision the failure area of possible fracture origin $[23,32]$.

As study's limitations is important to relate that a single compressive load to failure not replicate all of the clinical loads to which the restoration is exposed. The thermocycling also can reduce the bond strength between a cemented restoration increase the failure susceptibility $[32,33]$. The isotropic material simulated in the finite element study cannot be found in the clinics and patient's occlusion can modify the load application pattern [32]. It is also important to note that, for acrylic resin, incomplete polymerization with residual monomer unreacted promotes high degree of water absorption, deterioration of intrinsic pigments and dissolution of material components $[29,33]$ and further studies with mechanical aging simulation should also be performed.

\section{Conclusion}

Chairside digital workflow should be performed aiming to improve the indirect restoration mechanical response, however an anatomy design with higher cusp angulation and more evident occlusal sulcus can increase the stress concentration and reduce the fracture load for acrylic resin CAD/CAM crowns.

\section{Acknowledgments}

The authors would like to thank São Paulo Research Foundation (FAPESP) with the grants no 2013/14831-1 and no 2014/006684.

\section{References}

1. Abdullah AO, Tsitrou EA, Pollington S. Comparative in vitro evaluation of CAD/CAM vs conventional provisional crowns. J Appl Oral Sci 2016; 24(3):25863.
2. Rodrigues VA, Dal Piva AO, Yamaguchi CA, Borges AL, Mukai MK, Tribst JP. Effect of framework type on survival probability of implant-supported temporary crowns: An in vitro study. J Clin Exp Dent 2020; 12(5):433-9.

\section{Reeponmaha T, Angwaravong} O, Angwarawong T. Comparison of fracture strength after thermo-mechanical aging between provisional crowns made with CAD/CAM and conventional method. J Adv Prosthodont 2020; 12(4):218-24.

4. Winter A, Schurig A, Rasche E, Rösner F, Kanus L, Schmitter M. The flexural strength of CAD/CAM polymer crowns and the effect of artificial ageing on the fracture resistance of CAD/CAM polymer and ceramic single crowns. J Mater Sci Mater Med 2019; 31(1):9.

5. Alt V, Hannig M, Wöstmann B, Balkenhol M. Fracture strength of temporary fixed partial dentures: CAD/CAM versus directly fabricated restorations. Dent Mater 2011; 27(4):339-47.

6. Bowley JF, Ichim IP, Kieser JA, Swain MV: FEA evaluation of the resistance form of a premolar crown. J Prosthodont 2013; 22(4):304-12. 
7. Sornsuwan T, Swain MV. Influence of occlusal geometry on ceramic crown fracture; role of cusp angle and fissure radius. J Mech Behav Biomed Mater 2011; 4(7):1057-66.

\section{Zhang Z, Sornsuwan T,}

Rungsiyakull C, Li W, Li Q, Swain MV. Effects of design parameters on fracture resistance of glass simulated dental crowns. Dent Mater 2016; 32(3):373-84.

9. Shahmoradi M, Wan B, Zhang Z, Wilson T, Swain M, Li Q. Monolithic crowns fracture analysis: The effect of material properties, cusp angle and crown thickness. Dent Mater 2020; 36(8):1038-51.

10. Dal Piva AO, Tribst JP, Borges $A L$, de Melo RM, Bottino MA. Influence of substrate design for in vitro mechanical testing. J Clin Exp Dent 2019; 1(11):119-25.

11. Kelly JR, Rungruanganunt $P$, Hunter B, Vailati F. Development of a clinically validated bulk failure test for ceramic crowns. J Prosthet Dent. 2010

Oct;104(4):228-38.

12. Souza AC, Xavier TA, Platt JA, Borges AL. Effect of base and inlay restorative material on the stress distribution and fracture resistance of weakened premolars. Oper Dent 2015; 40(4):158-66.
13. Soares CJ, Pizi EC, Fonseca RB, Martins LR. Influence of root embedment material and periodontal ligament simulation on fracture resistance tests. Braz Oral Res. 2005 Jan-Mar;19(1):116. doi: 10.1590/s180683242005000100003. PMID: 16229350.

14. Tribst JPM, Monteiro JB, Venturini $A B$, Pereira GKR, Bottino MA, Melo RM, Valandro LF. Fatigue Failure Load of Resinbonded Simplified Lithium Disilicate Glass-Ceramic Restorations: Effect of Ceramic Conditioning Methods. J Adhes Dent. 2019;21(4):373-381.

15. Tribst JP, Dal Piva AO, Madruga CF, Valera MC, Bresciani E, Bottino MA, de Melo RM. The impact of restorative material and ceramic thickness on CAD \CAM endocrowns. J Clin Exp Dent. 2019; 1;11(11):969-977.

16. Penteado MM, Tribst JPM, Dal Piva AM, Ausiello $P$, Zarone $F$, Garcia-Godoy F, Borges AL. Mechanical behavior of conceptual posterior dental crowns with functional elasticity gradient. Am J Dent. 2019; 32(4):165-168.

17. Calderon PDS, Kogawa EM, Lauris JRP, Conti PCR. The influence of gender and bruxism on the human maximum bite force. J Appl Oral Sci 2006;14(6):448-53.
18. Karaman T, Eser B, Altintas E, Atala $\mathrm{MH}$. Evaluation of the effects of finish line type and width on the fracture strength of provisional crowns. Odontology 2020; 1-6.

19. Dureja I, Yadav B, Malhotra P, Dabas N, Bhargava A, Pahwa R. A comparative evaluation of vertical marginal fit of provisional crowns fabricated by computer-aided design/computer-aided manufacturing technique and direct (intraoral technique) and flexural strength of the materials: An in vitro study. J Indian Prosthodont Soc 2018; 18(4):314-20.

20. Muric A, Gokcen Röhlig B, Ongul D, Evlioglu G. Comparing the precision of reproducibility of computer-aided occlusal design to conventional methods. J Prosthodont Res 2019; 63(1):110-4.

21. Fasbinder DJ, Poticny DJ. Accuracy of occlusal contacts for crowns with chairside CAD/CAM techniques. Int J Comput Dent 2010; 13(4):303-16.

22. Wan B, Shahmoradi M, Zhang Z, Shibata Y, Sarrafpour B, Swain M, Li Q. Modelling of stress distribution and fracture in dental occlusal fissures. Scientific reports 2019; 9(1):1-10. 
23. Tribst JPM, Borges ALS, SilvaConcílio LR, Bottino MA, Özcan M. Effect of Restorative Material on Mechanical Response of Provisional Endocrowns: A 3DFEA Study. Materials 2021; 14(3):649.

24. Syam S, Soegiharto BM, Siregar

E. Stress distribution of maxillary anterior retraction using miniscrew with anterior hook on continuous wire (3D simulation finite element analysis). J Int Dent Medical Res 2018; 11(3):791-798.

25. Archangelo KC, Penteado MM, Dal Piva AMDO, Nogueira AS, Tribst JPM, Borges A LS. Stress distribution and failure load of multilayer and monolayer glass ceramic. Braz Dent Scii. 2019; 22(1), 17-22.

26. Costa VL, Tribst JP, Borges AL. Influence of the occlusal contacts in formation of Abfraction Lesions in the upper premolar. Braz Dent Sci. 2017; 20:115-123.

27. De Andrade GS, Tribst JPM, Orozco El, Augusto MG, Bottino MA, Borges AL, Anami LC, Saavedra GD. Influence of different post-endodontic restorations on the fatigue survival and biomechanical behavior of central incisors. Am J Dent. 2020; 33(5):227-234.
28. Saisadan D, Manimaran P, Meenapriya PK. In vitro comparative evaluation of mechanical properties of temporary restorative materials used in fixed partial denture. J Pharm Bioallied Sci. 2016 Oct;8(Suppl 1):S105-S109. 29. Türp JC, Greene CS, Strub JR. Dental occlusion: a critical reflection on past, present and future concepts. J Oral Rehabil 2008; 35(6):446-53.

30. Silva GR, Silva NR, Soares PV, Costa AR, Fernandes-Neto AJ, Soares CJ. Influence of different load application devices on fracture resistance of restored premolars. Braz Dent J. 2012;23(5):484-9.

31. Ausiello P, Gloria A, Maietta S, Watts DC, Martorelli M. Stress

Distributions for Hybrid Composite Endodontic Post Designs with and without a Ferrule: FEA Study. Polymers (Basel). 2020 Aug 16;12(8):1836.

32. Tribst JPM, Dal Piva AMDO, Lopes GC, Borges ALS, Bottino MA, Özcan M, et al. Biaxial flexural strength and Weilbull characteristics of adhesively luted hybrid and reinforced CAD/CAM materials to dentin: effect of self-etching ceramic primer versus hydrofluoric acid etching. J Adhes Sci Technol. 2020; 34(12):1253-68
33. Reeponmaha T, Angwaravong $\mathrm{O}$, Angwarawong T. Comparison of fracture strength after thermo-mechanical aging between provisional crowns made with CAD/CAM and conventional method. J Adv Prosthodont. 2020 Aug;12(4):218-224. 